\title{
Aspectos Subjetivos da Amamentação e Desmame: Evidências em Três Casos
}

\author{
Andrea Gabriela Ferrari ${ }^{1}$ \\ Universidade Federal do Rio Grande do Sul \\ Evandro de Quadros Cherer \\ Universidade de Brasília \\ Cesar Augusto Piccinini \\ Universidade Federal do Rio Grande do Sul
}

\begin{abstract}
RESUMO - Este estudo investigou aspectos subjetivos da amamentação e do desmame aos três e oito meses de vida do bebê. Utilizou-se delineamento de estudo de caso coletivo, sendo que três mães primíparas responderam a uma entrevista sobre diversos aspectos da maternidade, sobretudo, a amamentação e o desmame. Análise de conteúdo qualitativa das respostas, baseada na psicanálise, revelou que a amamentação pode indicar uma relação incestuosa mãe-bebê, na qual este pode ser tomado como objeto de desejo materno. As mães também relataram experiências de prazer e desprazer associadas à amamentação, evidenciando ambivalências e dificuldades presentes. Portanto, este estudo indicou que a amamentação e o desmame abarcam significados e implicações para além do biológico, remetendo à relação mãe-filho, bem como à história constitutiva da própria mãe.
\end{abstract}

Palavras-chave: amamentação, desmame, relação mãe-criança, maternidade, psicanálise

\section{Subjective Aspects of Breastfeeding and Weaning: Evidence from Three Cases}

\begin{abstract}
This study aimed to investigate subjective aspects of breastfeeding and weaning at three and eight months of baby's life. A longitudinal multiple case study design was used. Three primiparous mothers were interviewed about various aspects of motherhood, in particular, breastfeeding and weaning. Analysis of qualitative content of maternal responses, based on psychoanalysis, revealed that breastfeeding can be an indication of an incestuous mother-infant relationship in which this can be taken as the object of maternal desire. Mothers also reported the experiences of pleasure and displeasure associated with breastfeeding, highlighting the existing difficulties and ambiguities present. Thus, the study indicates that breastfeeding and weaning encompass meanings and implications beyond the biological, referring to the mother-child relationship, as well as the mother's constitutive story.
\end{abstract}

Keywords: breastfeeding, weaning, mother child relations, motherhood, psychoanalysis

Nos últimos anos, ações governamentais e da Organização Mundial de Saúde (OMS) têm se mostrado contundentes no intuito de erradicar a mortalidade infantil devido a problemas decorrentes da miserabilidade dos países do terceiro mundo, incentivando, com isso, o aleitamento materno. Essas campanhas fazem referência às vantagens para o desenvolvimento afetivo, cognitivo e físico do bebê, assim como à satisfação gerada na mãe que amamenta em relação ao exercício da sua maternidade. Desse modo, nos hospitais públicos, é frequente que se impeça o uso de chupetas e complementos oferecidos na mamadeira, uma vez que isso implicaria no desmame precoce do bebê. Nesse sentido, os programas de aleitamento materno oferecidos para as gestantes e puérperas nos hospitais públicos do país se baseiam no aleitamento materno exclusivo durante os primeiros seis meses do bebê, desaprovando veementemente o oferecimento de águas, chás e chupetas. Além disso, aconselha-se oferecer o seio a qualquer manifestação de desconforto do bebê (Campagnolo, Louzada, Silveira,\& Vitolo, 2012; Cotrim, Venancio,\& Escuder, 2002; OMS, 2001).

1 Endereço para correspondência: Rua Ramiro Barcelos, 2600, Térreo, Porto Alegre, RS, Brasil. CEP: 90.035-003.E-mail: ferrari.ag@hotmail. com
Em contrapartida, a partir da psicanálise (Winnicott, 1968/2006; Levin, 2005; Queiroz, 2005), mesmo que se reconheçam as vantagens da amamentação, pode-se questionar a forma como essas indicações são transmitidas para as mães, principalmente àquelas que têm o primeiro filho, como um imperativo que, se descumprido, terá consequências devastadoras na vida da criança. De fato, a experiência em atendimento clínico dos autores deste estudo indica que há algumas mães que possuem muita dificuldade em amamentar apesar de serem mães zelosas e cuidadosas com seu bebê.

A respeito disso, Winnicott (1968/2006), apesar de valorizar as especificidades da amamentação, criticou aquilo que chamou de propaganda a favor da amamentação, compreendendo ser prejudicial forçar uma mulher a amamentar seu filho caso ela não se sinta confortável nessa tarefa. Para esse autor, existem outros modos por meio dos quais o bebê pode ter intimidade física com a mãe, na medida em que segurar e manipular o bebê, por exemplo, seria mais importante, em termos psíquicos, do que a amamentação em si (Winnicott, 1968/2006). Porém, Winnicott (1945/1977a) também compreendeu que a amamentação é uma questão pertinente à relação mãe-bebê, distinguindo-se das demais formas de nutrir. Segundo o autor, espera-se que a mãe, 
com seu seio, além de alimentar, ofereça alento ao seu filho. Nesse sentido, a amamentação pode ser uma via privilegiada para apaziguar a angústia do bebê, aproximando-se da continuidade intrauterina.

Além dessas contribuições, Winnicott (1968/2006) apontou para uma fantasia recorrente em mães que amamentam: o temor de que o bebê a devore. Com isso, para o autor, apesar de algumas mães compreenderem ser seu leite, oferecido por meio da amamentação, algo importante para acalmar seu bebê, podem surgir sentimentos ambivalentes a respeito de sentir-se sugada e escravizada por esse pequeno ser. Ao encontro dessas ideias, Middlemore (1974) afirmou que $\mathrm{o}$ ato de amamentar pode ser afetado pelas fantasias maternas de ser devorada, de esvaziar-se, de não existir mais e se sentir despossuída de si mesma. Esses conflitos inconscientes podem conduzir a mãe a diversas dificuldades na amamentação, podendo essa tarefa fracassar por essas motivações inconscientes ou ainda ser recusada de modo consciente.

Apesar dessas questões, conforme Levin (2005), o amamentar foi se tornando, ao longo da história, o representante da dedicação materna em relação ao bebê, fundamental à sua sobrevivência, em função da sua total dependência inicial. $\mathrm{O}$ autor considera a amamentação uma cena fundante do sujeito, visto que cria um ponto de encontro entre o desenvolvimento do corpo e da estruturação subjetiva. Para esse autor, é por meio da doação realizada pela mãe de uma parte de seu corpo que se torna possível o enlace a um objeto causa de desejo que impulsiona o bebê à vida. Para que a mãe se permita fazer essa doação, ela precisa encarar uma dualidade pulsional em seu próprio corpo entre o "peito materno" e o "peito de mulher" (Levin, 2005, p. 98), dualidade que permite que a criança encontre ali seu lugar de filiação e se desvincule, tanto para a mãe quanto para o filho, o mamar como função alimentícia e a amamentação como função erógena.

Desse modo, no intuito de enfatizar o entendimento da amamentação e desmame para além da sua vertente biológica e nutricional, pode-se recorrer também ao entendimento de Dolto (2004) em relação ao conceito de castrações humanizantes, especificamente à castração oral. Para a autora, a castração oral incide na renúncia da satisfação da pulsão oral na relação corpo a corpo mãe-bebê. Assim, implica que a mãe deixe de considerar-se como única responsável pela sobrevivência do bebê e única interprete das suas necessidades. Por sua vez, o efeito humanizante no bebê refere-se ao acionamento do desejo de comunicar-se com outros. Para Dolto, o desmame é a condensação de um processo constitutivo maior que terá efeitos tanto nos futuros relacionamentos da mãe, na retomada de seus interesses pessoais, e no bebê, na possibilidade de iniciar a ampliação dos seus relacionamentos afetivos para além da mãe.

A partir dessa perspectiva, pode-se entender que a amamentação abrange a troca de olhares, toques e sensações que compõem a imago materna (Sales, 2005), implicando um período importante e único na constituição psíquica do bebê (Sampaio et al., 2010). Com isso, para Queiroz (2005), a amamentação, além de compreender o seio, a boca e o leite, abarca também todo o processo de (in)satisfação da relação mãe-bebê, referindo-se ao tempo concedido ao bebê a fim de desfrutar da relação incestuosa com sua mãe.

Todavia, conforme Queiroz (2005), na medida em que, na nossa cultura, o gozo é interditado para os sujeitos falantes, a relação incestuosa estabelecida inicialmente entre a mãe e o bebê deve posteriormente ser interditada e submetida à castração humanizante. Esse processo de interdição possibilitará que o bebê gradualmente tenha acesso ao simbólico. É nesse contexto que o desmame implica a renúncia do desejo de fusão ao nível imaginário, permitindo à mãe e ao bebê substituírem sua satisfação corpo a corpo por um prazer baseado na satisfação das relações mediadas pela linguagem (Lighezzolo, Boubou, Souillot, \& Tychey, 2005).

Assim, no que diz respeito ao desmame, Levin (2005) afirmou que este antecede a alteração de posição relativa ao Outro materno (primordial). No entanto, apesar do desmame marcar o final do aleitamento, não implica o fim do mamar, visto que o bebê precisará continuar mamando do desejo do Outro. $\mathrm{O}$ autor refere que o desmame coincide com o estádio do espelho (Lacan, 1949/1998), momento constitutivo no qual o infans adquire uma unidade corporal da qual passa a ter um maior domínio e permite modificar as suas relações cotidianas. Para Levin, o bebê apenas consegue se desmamar na medida em que incorpora a imagem do seio materno; e, de modo semelhante, a mãe também é desmamada, por sua vez, da imagem do bebê de peito. Desse modo, a perda dessa configuração reorganizará o desejo materno a fim retomar seu corpo.

Nesse cenário, para Sampaio et al. (2010), o desmame precoce pode estar relacionado à problemas de vínculo na relação mãe-bebê e na constituição da maternidade, enquanto que o desmame tardio pode estar associado ao excesso psicoafetivo materno, revelando dificuldades na entrada de terceiros na relação mãe-bebê. Com isso, o prolongamento da amamentação pode tornar-se sinônimo da postergação da castração oral, exclusão da dimensão paterna enquanto terceiro, bem como a manutenção da relação corpo a corpo da mãe com o bebê, sem mediação pela linguagem (Lighezzolo et al., 2005).

Como visto acima, a literatura psicanalítica indica que a amamentação e o desmame são processos cruciais na relação mãe-bebê, tendo importantes repercussões na subjetivação do bebê, bem como efeitos estruturantes no psiquismo infantil e materno (Sampaio et al., 2010). Desse modo, considerandose que a amamentação e o desmame possuem significados e implicações para além do biológico, o presente estudo teve como objetivo investigar aspectos subjetivos no processo de amamentação e desmame aos três e oito meses de vida do bebê.

\section{Método}

\section{Participantes}

Participaram deste estudo três mães primíparas e seus bebês que, no início do estudo, tinham três meses de idade. Uma das mães, denominada aqui de Sandra, tinha 32 anos, ensino médio completo, trabalhava no comércio da família 
e residia com seu marido e filho. A segunda participante, denominada Giovana, tinha 34 anos, ensino superior completo, trabalhava como secretária executiva e residia com seu marido e filho. Por fim, Daniela tinha 28 anos, ensino superior incompleto, trabalhava como vendedora e residia com seu marido e filho.Todas as díades integravam o projeto intitulado Estudo Longitudinal de Porto Alegre: Da Gestação à Escola (ELPA; Piccinini, Tudge, Lopes, \& Sperb, 1998-2012) ${ }^{1}$. O estudo foi aprovado pelo Comitê de Ética da UFRGS e pelo Comitê de Ética dos hospitais envolvidos na indicação das participantes. Para fins do presente estudo, foram utilizados os primeiros três casos acompanhados pela primeira autora do presente estudo e que ofereciam uma oportunidade de aprendizado (Stake, 1994).

\section{Delineamento, Instrumentos e Procedimentos}

Foi utilizado um estudo de caso coletivo (Stake, 1994), de caráter longitudinal, com o objetivo de investigar aspectos subjetivos no processo de amamentação e desmame aos três e oito meses de vida do bebê. Para o presente estudo, foram utilizados os dados dos seguintes instrumentos do Projeto ELPA: Entrevista de dados demográficos do casal (Grupo de Interação Social, Desenvolvimento e Psicopatologia [GIDEP], 1998a), Entrevista sobre a experiência da maternidade - primeiro trimestre do bebê (GIDEP, 1998b), Entrevista sobre o temperamento do bebê - primeiro trimestre do bebê (GIDEP, 1998c), Entrevista sobre a experiência da maternidade - oitavo mês do bebê (GIDEP, 1998d) e Entrevista sobre o temperamento do bebê - oitavo mês do bebê (GIDEP, 1998e). Trata-se de entrevistas estruturadas, realizadas de forma semidirigida. Essas entrevistas abordavam extensamente os sentimentos e as expectativas sobre a maternidade, sobre o processo de amamentação e desmame, sobre o bebê e futuro do filho desde a descoberta da gravidez, assim como sobre a experiência da maternidade naquele momento. As entrevistas foram realizadas individualmente, sendo gravadas em meio digital e transcritas posteriormente na íntegra.

\section{Resultados e Discussão}

A partir do conteúdo das falas das mães nas entrevistas, bem como da literatura psicanalítica, buscou-se investigar aspectos subjetivos nos processos de amamentação e desmame aos três e oito meses de vida do bebê. Inicialmente os casos serão apresentados separadamente, sendo ilustrados por meio dos relatos das próprias mães e discutidos à luz da

1 Esse estudo teve por objetivo investigar aspectos subjetivos e comportamentais das interações iniciais pai-mãe-bebê, bem como o impacto de fatores iniciais do desenvolvimento nas interações familiares, no comportamento social de crianças pré-escolares e na transição para a escola de ensino fundamental. O estudo iniciou acompanhando 81 gestantes primíparas, que não apresentavam intercorrências clínicas seja com elas mesmas ou com o bebê e que foram acompanhadas em várias coletas de dados desde a gestação até os sete anos das crianças (gestação, $3^{\circ}, 8^{\circ}, 12^{\circ}, 18^{\circ}, 24^{\circ}, 30^{\circ}$ meses e $6^{\circ}$ e $7^{\circ}$ ano de vida da criança). literatura. Ao final,serão examinadas eventuais semelhanças e particularidades entre os casos.

\section{Caso Sandra: O Seio como Índice de uma Relação Incestuosa}

Na entrevista realizada aos três meses de vida de seu filho, Sandra relatou que o amamentava no peito e que não queria deixá-lo com nenhuma outra pessoa além dela, desejando que ele permanecesse sempre consigo. Relatou que assumia os cuidados com o bebê quase que exclusivamente, ausentandose apenas em raras ocasiões, tendo pensado distanciar-se do filho apenas quando não existisse outra possibilidade e quando ele estivesse mais crescido. Nesse cenário, Sandra expressou ter grande satisfação em amamentar, afirmando que seu filho se expressava por gemidos durante a amamentação e que ele tinha a mania de dormir sempre agarrado com ela: " $\mathrm{Eu}$ gosto, eu acho lindo ver ele mamar!". Assim, a amamentação pode ser vista como proporcionando uma satisfação narcísica, na medida em que a oralidade poderia estar sendo a única intermediária do bebê com o mundo (Dolto, 2004; Freud, 1914/2004).

Ainda na entrevista do terceiro mês, Sandra relatou também que diversas vezes oferecia o seio ao filho, mesmo quando ele não estava com fome. Contou ter acostumado o bebê a essa dinâmica, na medida em que, a qualquer queixa deste, oferecia o seio, afirmando em seguida: " $E u$ sempre botava na minha cabeça que eu ia amamentar, só tinha dúvida se ele ia pegar!". Após revelar essa dúvida, Sandra expressou que seu filho iria mamar por um longo período de tempo. Ela afirmou esperar que o bebê mamasse até o primeiro ano de vida, não mais do que isso, uma vez que esse se tornaria um "bebezão". Contudo, para Sales (2005),quando o seio é oferecido em livre demanda ao bebê, a amamentação pode se tornar mecânica, podendo criar dificuldades para que a mãe apreenda o bebê como um sujeito desejante que também se expressa para além de suas necessidades orgânicas.

Apesar de Sandra ter afirmado não terem ocorrido muitas mudanças em sua vida com a maternidade, posteriormente acabou admitindo que seu filho era amamentado muitas vezes durante a noite, sendo a isso associadas diversas alterações na vida do casal. Nesse sentido, Sandra contou amamentar seu filho conforme ele a solicitava, não seguindo horários predefinidos. No entanto, para ela, o bebê mamava em excesso, uma vez que ela teria o acostumado com esse ritmo. Ademais, Sandra reafirmou que seu filho dormia sempre agarrado a ela, acordando apenas para ser amamentado durante a noite. Repetidamente Sandra dava o seio a fim de acalmar o bebê, duvidando que alguém além dela conseguisse acalmá-lo. No entanto, apesar de ter dificuldades, Sandra permitiu que seu marido tentasse acalmar o filho, o que ele conseguia ainda que esporadicamente. Nesse cenário, é plausível se supor o emprego do seio como desvinculado de sua função nutritícia (Sampaio et al., 2010), o qual pode ser colocado estritamente em uma relação incestuosa corpo a corpo (Queiroz, 2005). Quanto a isso, conforme Sales (2005), o uso do seio materno diante de qualquer expressão de desconforto do bebê pode conduzir a uma fusão entre 
seio e leite, na qual o seio passa a ser uma fonte de leite deserotizada e mecânica. Já com relação ao bebê, o seio, além de ser o único objeto capaz de satisfazer sua fome, é também empregado para fazê-lo calar e sedar. Sendo assim, pode-se supor que a amamentação seria um possível indicador da relação incestuosa estabelecida entre Sandra e seu filho, em vista que ela se colocava como única mediadora entre o bebê e os outros, parecendo colocá-lo como correspondendo ao seu objeto de desejo (Lacan 1958/1999).

Aos oito meses de vida do bebê, Sandra contou estar passando por dificuldades concernentes à alimentação de seu filho. Ela relatou que tentou alimentá-lo com comida a partir do quinto mês, mas ele não estava aceitando, demandando a amamentação de duas em duas horas: "O problema é $O$ mamar (...) se eu não dou, ele chora, ele se bate". Além de ter expressado a dificuldade em inserir outros alimentos na alimentação do bebê, Sandra evidenciou aspectos da relação com seu filho que eram permeadas pelo seio, pelo corpo a corpo, uma vez que o bebê dormia na cama juntamente com ela e seu marido: "Já teve noites que eu notei que ele só quer dormir botando a boca no bico do seio, ele dorme e não mama". Relativo a essa dinâmica, Sandra voltou a se responsabilizar, como já havia feito aos três meses do bebê, afirmando que oferecia o seio diante qualquer solicitação do filho, não sabendo como desmamá-lo. Nesse contexto, a partir do entendimento de que o desejo de desmamar passa pela mãe (Winnicott, 1945/1977b), compreende-se que o processo de desmame pode tornar-se difícil para a díade mãe-bebê e pode ser vivenciado como uma separação extremamente dolorosa também para a mãe (Carrascoza, Costa Junior, \& Moraes, 2005). Com isso, a mãe precisa ser desmamada da imagem do bebê do seio (Levin, 2005), processo esse que pode encontrar empecilhos considerando a relação incestuosa que a mãe possui com o bebê e que está também associada às dificuldades na inserção de terceiros (Sampaio et al., 2010).

Ainda na entrevista do oitavo mês, Sandra permaneceu relatando as dificuldades em alimentar seu filho com outros alimentos fora o leite materno. A partir desse contexto, é plausível supor que essas dificuldades não se restringiam apenas em saciar as necessidades alimentares do bebê, visto que Sandra evitava afastar-se do seu filho, uma vez que este solicitava constantemente o seio materno, o que foi associado por ela como causando implicações na dinâmica do casal. Com isso, Sandra e seu marido tinham a relação conjugal diretamente afetada pela amamentação do bebê, a qual era empecilho para passeios e para a vida sexual. Além disso, o filho apenas dormia após ser amamentado segurando a mão materna. Diante disso, pode-se pensar que a dependência do bebê do corpo materno, assim como da mãe de seu filho, repercutiu de modo a dificultar a aceitação do bebê de outros alimentos e inclusive de encontrar diferentes modos de aplacar suas inquietações (Sales, 2005).

\section{Caso Giovana: Dificuldades e Ambivalências em Deixar-se Mamar}

$\mathrm{Na}$ entrevista realizada aos três meses de vida de seu filho, Giovana relatou que este havia nascido prematuro aos sete meses de gestação. Assim, após nascer, o filho permaneceu cinco dias na incubadora, sendo alimentado com soro, uma vez que não aceitava a amamentação. Após esse período, o bebê aceitou ser amamentado, o que era intercalado com leite em pó. Entretanto, Giovana relatou não ter tolerado permanecer muito tempo com o bebê no hospital, necessitando fazer o que referiu como "fugidas". A partir disso, pode-se pensar que Giovana fugia do imprevisto a que foi submetida, de todo esse cenário angustiante envolvendo o nascimento pré-termo. Nascimento que se distanciou muito em relação ao que ela tinha imaginado e idealizado, na medida em que, com a gestação, ocorre a montagem de um bebê imaginado e, juntamente com este, surgem as expectativas parentais (Brazelton \& Cramer, 1992; Fleck \& Piccinini, 2013; Lebovici, 1987; Stern, 1997).

Nos três primeiros meses de vida do bebê, Giovana passou por intensas dificuldades para amamentar seu filho, passando, com isso, a pensar que não teria leite suficiente para alimentálo, bem como a questionar sua capacidade de cuidá-lo: "Ele não tá conseguindo mamar ou estou com pouco leite". Desse modo, a fim de que o bebê não se acostumasse com a mamadeira, Giovana passou a oferecer, por meio de uma seringa, leite em pó para seu filho. Nesse contexto, podese pensar que o alimento artificial era empregado diante de certa desvalorização da figura materna (Sampaio et al., 2010), corroborando o estudo de Ramos e Almeida (2003), segundo o qual o processo de amamentação e desmame esteve associada à culpa, uma vez que as mães alegaram ter pouco ou fraco leite.

Diante disso, o marido de Giovana a estimulava quanto à amamentação, afirmando que ela dispunha de leite o suficiente, incentivando-a a oferecer o seio ao filho. No entanto, o bebê sofria de muitas cólicas, as quais eram associadas por Giovana à mistura do leite materno com o leite em pó, assim como a alimentos que ela própria ingeria: "Será que a cólica pode ser da minha alimentação, porque poderia ser da minha alimentação, mas eu estava me cuidando, eu estava comendo coisinhas saudáveis". Desse modo, a amamentação também exigia de Giovana não comer alimentos que, em sua concepção, poderiam ocasionar cólicas no bebê, o que poderia estar sendo experienciado como um sacrifício (Nakano \& Mamede, 1999).

Entretanto, no final do primeiro trimestre do bebê, essa dinâmica da amamentação alterou-se a partir do momento em que Giovana foi visitar sua irmã, que também tinha um bebê da mesma idade. Esta afirmou categoricamente para Giovana que ela tinha leite suficiente, não necessitando do leite em pó para alimentar seu filho. Ademais, uma cena em especial foi destacada por Giovana, a saber, quando sua irmã amamentou o bebê. Desde então, o filho era amamentado exclusivamente ao seio e não chorava mais de cólica, tendo Giovana conseguido se disponibilizar para seu filho de modo semelhante ao que sua irmã fazia com o sobrinho: "E a partir de lá, eu só dei leite materno". Pode-se pensar que foi a partir da identificação com sua irmã que Giovana conseguiu deixar-se mamar por seu filho, reconhecendo-se enquanto mãe, assim como possuidora da capacidade de cuidar e alimentar o bebê. Relativo a isso, Winnicott (1967) afirmou que uma mãe possui plena capacidade de cuidar e de amar seu filho, desde que ela também se sinta amada e cuidada, o que foi possível para Giovana no encontro com 
sua irmã, possibilitando que ela se relacionasse desde um outro lugar com o seu filho.

Apesar de ter conseguido amamentar, Giovana expressou sentir-se cansada da dependência de seu filho e da relação corpo a corpo que existia entre os dois. Queixava-se de não ter tempo disponível para suas próprias atividades, sentindo-se sugada pelo bebê (Middlemore, 1974; Winnicott, 1968/2006), repercutindo em sua disponibilidade a seu filho: "Quando o meu filho começar a comer comidinha e não precisar muito da teta, eu vou dormir". De certo modo, ao sentirse esvaziada de si nessa relação, Giovana deparou-se com dificuldades para amamentar o bebê, desejando e ansiando pelo desmame como relatado na literatura (Queiroz, 2005). A amamentação, portanto, pôde ser experienciada de modo ambivalente, ocasionando desprazer, o qual tipicamente era velado, visto que se contrapunha ao ideal de maternidade (Feliciano \& Souza, 2011; Nakano \& Mamede, 1999).

$\mathrm{Na}$ entrevista dos oito meses de vida do bebê, Giovana relatou que havia desmamado o filho aos cinco meses e meio, após ter retornado ao trabalho e deixado o filho sob os cuidados de sua sogra. Inicialmente, Giovana retornava todos os dias às onze da manhã e às cinco da tarde para amamentar, relatando querer dar de mamar como muitas mulheres que, mesmo trabalhando, permanecem amamentando. Entretanto, quando ela chegava em casa, sua sogra já havia alimentado o bebê, dificultando o aceite do seio: "Ele não queria mais a teta, chegava com teta cheia e ele não queria. Dava uma chupadinha, tirava e não queria mais. Ai tá né, então vamos desmamar então. Aí eu não dei mais".

Às inquietações da prematuridade e amamentação, somava-se o fato de seu filho não estar engatinhando, questões essas que eram apontadas por sua sogra e que eram difíceis de serem elaboradas por Giovana. Além de ter boicotado a amamentação, a sogra era descrita como sabendo cuidar do bebê e como apontando as falhas que Giovana teria no exercício de sua maternidade. Desse modo, apesar de ter desejado, como sua irmã, amamentar seu filho, Giovana apenas conseguiu fazê-lo tardiamente e por um curto período de tempo.

Inicialmente, a dependência absoluta do filho nascido pré-termo em relação aos cuidados maternos a deixava extremamente cansada. Giovana ansiava que seu filho crescesse, uma vez que tinha dificuldades em aceitar as suas demandas. Posteriormente, obteve satisfação por meio da amamentação ao realizá-la, o que se tornou representante para si de uma maternidade plena. Todavia, essa dinâmica debilitou-se desde que Giovana deixou de amamentar, estando mais uma vez à mercê das questões que a perturbavam, assim como de discursos que perturbavam a frágil organização da sua maternidade. A respeito disso, compreende-se que a amamentação pode se constituir em um processo permeado por sentimentos ambíguos e contraditórios, os quais podem proporcionar sofrimento para a mãe em sua relação com o bebê (Ramos \& Almeida, 2003). No entanto, também pode ser difícil para uma mulher não conseguir amamentar, visto que pode haver uma associação entre ser uma boa nutriz e ser mãe (Nakano \& Mamede, 1999).

\section{Caso Daniela: O Prazer e Desprazer em Amamentar}

Na entrevista do terceiro mês de vida do bebê, Daniela relatou que ser mãe estava sendo muito cansativo, ocupando-a intensamente com os cuidados com o filho, entre estes a amamentação. Daniela afirmou que inicialmente ela tinha muito leite e que este vinha com grande intensidade. Entretanto, ela contou que seu filho sofria com refluxo e de muitas cólicas e, por isso, passava grande parte da noite chorando, impossibilitando com que ela dormisse. Associado a esse contexto, Daniela expôs ter passado a contar com a ajuda de sua mãe, a qual passou a alimentar o bebê na mamadeira: "Tinha vezes que eu ficava tão estressada que eu não tinha nem leite para dar, minha mãe tinha que dar mamadeira". Essa entrega aos cuidados com o bebê, reforçada pelas constantes cólicas de seu filho, pode ter provocado em Daniela a dificuldade em amamentar, visto que, nesse cenário, podem ocorrer dificuldades nas trocas de prazer e na formação de vínculos de intimidade (Feliciano \& Souza, 2011). Com isso, Daniela associou os problemas com seu filho e, por consequência, seu cansaço e estresse, à perda do leite, evidenciando que conflitos podem efetivamente dificultar e inclusive incapacitar uma mãe de amamentar (Middlemore, 1974; Nakano \& Mamede, 1999; Queiroz, 2005).

Assim, Daniela relatou acreditar que o bebê aceitava a mamadeira por estar com muita fome, não se acalmando por completo, mas, de qualquer modo, permitindo que ela conseguisse dormir e, por conseguinte, descansasse um pouco. Ela expôs ter ficado muito angustiada com as cólicas do filho, chorando juntamente com ele, uma vez que não sabia o que fazer diante dessa situação, recorrendo frequentemente ao hospital. Com efeito, a experiência de amamentar de Daniela estava sendo vivida como um sacrifício (Nakano \& Mamede, 1999), exigindo que ela se disponibilizasse intensamente ao bebê, inclusive controlando a sua própria alimentação: "Ele berrava muito e não comia nada, nada de especial. Eu só tomava leite, porque é bom para o leite coisinhas com queijo. Eu não comia nada de tempero! Toda a minha comida era especial, só com sal, para ver se passava as cólicas". Assim, corroborando o cansaço advindo da dedicação ao filho, Daniela acrescentou os cuidados que tinha com sua alimentação, o que evidenciava sua implicação e responsabilização nos problemas com o bebê.

Daniela também contou ter ficado preocupada em ter que voltar a trabalhar, não querendo colocar seu filho na creche, mas esperando que sua mãe e sogra pudessem ajudá-la a cuidar do bebê. Seu incomodo relacionava-se em ter que desmamar seu filho, já que ele não aceitava prontamente outro substituto como o bico ou a mamadeira. Quanto a isso, Daniela associou ter sido semelhante em sua infância, apenas aceitando a mamadeira em extremo caso de fome: "Ele vai ter que parar de mamar no peito. $O$ [bebê] não chupa bico, ele não gosta do gosto da borracha, eu fui igual. (...) Berra se tu põe mamadeira na boca dele. Ele só mama [na mamadeira] quando ele tá morrendo de fome! Minha mãe disse que eu era assim".

Nesse cenário, conforme Middlemore (1974), podese supor que a mais intensa das impressões acerca da amamentação se constitui a partir de conteúdos infantis, 
quando a mulher foi amamentada por sua própria mãe. Desse modo, Daniela pode ter reatualizado sua própria amamentação, na medida em que conteúdos se transmitem de mãe para filho, possibilitando, inclusive, que amamentar seja mais fácil caso a mãe tenha tido uma boa experiência de amamentação em sua infância (Queiroz, 2005). Nesse sentido, compreende-se que a amamentação e o desmame relacionam-se a aspectos relativos à oralidade da própria mãe (Winnicott, 1968/2006), sendo a partir da pré-história materna que traços inconscientes podem facilitar ou dificultar essa dinâmica (Feliciano \& Souza, 2011). Nesse contexto, pode-se pensar que Daniela estava inscrita em uma repetição inconsciente com o seu próprio filho, reproduzindo o modo que foi amamentada quando criança. No entanto, simultaneamente ela também estava tendo desejo de reparar a sua experiência infantil, insistindo em amamentar seu filho (Lighezzolo et al., 2005).

Ainda na entrevista realizada aos três meses de seu filho, Daniela relatou que as complicações das cólicas e refluxo de seu filho já haviam parado, possibilitando que ela se autorizasse a comer tudo o que gostaria novamente: "Agora comecei aos poucos a voltar a comer tudo, o [bebê] não sente mais nada". Com isso, a amamentação deixou de ser algo tão penoso para Daniela, passando a ser inclusive difícil distanciar-se do filho, assim como renunciar à relação de poder e dependência do bebê com ela (Sales, 2005). Desejando querer permanecer com o seu filho, Daniela resistia em voltar ao trabalho, postergando o seu próprio desejo de desmame (Winnicott, 1945/1977b): "Eu fico passando isso para ele, esta angústia de que eu não quero trabalhar, eu quero ficar com ele!".

Aos oito meses de seu filho, Daniela contou que seu filho queria ficar grudado com ela, sendo atribuído a esse comportamento do filho o reconhecimento de seu próprio desejo de permanecer em casa e cuidar do bebê. Com isso, Daniela decidiu não trabalhar mais, podendo, assim, aproveitar o seu filho, visto que acreditava que não teria outro. Entretanto, Daniela revelou que estava passando por problemas em relação à alimentação do bebê, o que dificultava o ganho de peso deste. Seu filho não aceitava bem os alimentos, apenas brincava com a comida, o que a irritava. Para Daniela, entre os possíveis motivos que dificultavam que seu filho ganhasse peso, estava à inquietação durante as refeições, característica que o bebê tinha semelhante a ela. Além disso, Daniela expôs existirem conflitos em relação ao seu marido, o qual tinha sobrepeso. Assim, Daniela associou passar para o filho o desejo de que ele não fosse como o pai. Nesse cenário, Daniela disse ter seguido todas as orientações médicas para desmamar seu filho, mas revelou acreditar que apenas teria êxito se permitisse que seu filho passasse fome: "Acho que só vai parar assim, de mamar quando passar fome e daí eu fico com pena, não vou fazer ele passar fome para parar de mamar né!'”. Desse modo, por sentir pena, Daniela relatou que, após insistir com os alimentos, ela o amamentava.

Assim como na entrevista do terceiro mês, aos oito meses, Daniela relatou novamente associar a amamentação também a algo desprazeroso, como um sacrifício, uma vez que, durante o inverno, ela saía de sua cama três vezes por noite para amamentar o bebê: "Para mim era um saco! Eu nunca durmo tranquila (...) fica os dois sentados assim congelando e depois ele volta para a cama e eu volto para o quarto. Isso três vezes durante a noite. É para matar!". Diante disso, Daniela contou que o filho passou a dormir junto a ela na cama do casal. No entanto, para isso, Daniela determinava que seu marido se retirasse da cama, deixando ela a sós com o bebê: "Eu ponho ele no lugar do [marido] e mando ele ir dormir no colchão". Apesar de queixar-se e expressar sentirse sugada pelos cuidados com o bebê (Middlemore, 1974; Winnicott, 1968/2006), Daniela demonstrava desfrutar dessa relação incestuosa, inclusive demarcando a ineficiência de seu marido enquanto operador da função paterna. O lugar que ela imputava ao bebê parecia ser daquele que a satisfazia, não permitindo que outros se interpusessem nessa relação. Quanto a isso, Lacan (1957/1995) afirmou ser essencial para o desmame primitivo a ação simbólica paterna, o que possibilitaria o acesso do infans ao mundo simbólico, assim como permitiria o desacoplamento simples e puro concernente à onipotência materna. Por fim, nesse contexto, Daniela reafirmou sua satisfação em amamentar, expressando sua dificuldade em desmamar-se da imagem do bebê do peito (Levin, 2005) e associando a isso a problemática do desmame para o filho, ou seja, a imposição da castração oral (Dolto, 2004) enquanto passagem do seio para outros alimentos: "Eu amo dar teta para ele, eu acho que é por isso que ele não para de mamar".

\section{Considerações Finais}

Em todos os casos estudados, constatou-se a vontade materna de fazer-se disponível ao filho e deixar-se mamar, ainda que isso se associasse, em alguns momentos, a dificuldades ou sacrifícios (Middlemore ,1974; Winnicott,1968/2006). A partir disso, é plausível se supor a relação formulada por essas mães entre a amamentação e o exercício pleno da maternidade, como se, enquanto mães, elas deveriam se entregar ao (des)prazer da amamentação, como um imperativo que efetivamente as tornasse mães (Feliciano \& Souza, 2011; Levin, 2005; Nakano \& Mamede, 1999).

Nesse contexto, especialmente, os casos de Sandra e Daniela evidenciaram a satisfação que o filho pode proporcionar à mãe, na medida em que ele pode ser tomado como correspondendo ao objeto de desejo materno. Com efeito, o próprio infans pode ocupar o lugar de objeto fálico, sendo, com isso, convocado à castração, a qual deve incidir também na mãe, que precisa ser privada do objeto de seu desejo (Lacan 1957/1995; 1958/1999). Ao ser submetido à castração simbolígena oral, o bebê deixa de ter sua mãe como única interprete da linguagem (Dolto, 2004), havendo uma partição simbólica, ação fundamental que compete ao processo de desmame (Rodulfo, 1990). Com isso, a renúncia a esse modo de relação incestuoso estaria de algum modo associado ao desmame, experiência que Sandra e Daniela encontraram dificuldades em efetuar (Sampaio et al., 2010). Por sua vez, no caso de Giovana, o desmame ocorreu pela sua dificuldade em sustentar seu lugar de mãe frente a um bebê pré-termo e ao saber parental da sogra. Essas contingências podem ter acionado vivências precoces da sua relação com sua própria mãe e fantasias inconscientes de devoramento 
(Middlemore, 1974; Winnicott, 1968/2006), que impediram o prazer na amamentação bem como a impeliram a um desmame resignado e doloroso.

Particularmente, o Caso Daniela também trouxe em questão a história constitutiva da própria mãe como relacionada à amamentação e ao desmame do filho. Associado a isso, essa mãe relatou as experiências de prazer e desprazer que podem se fazer atuantes na amamentação e no desmame. Com isso, percebeu-se a diversidade de sentimentos e aspectos que interferem na amamentação e, por conseguinte, no desmame. Com isso corrobora-se com o estudo de O’brien, Buikstra e Hegney (2008), o qual afirmou que fatores psicológicos individuais são mais preditivos quanto ao tempo de duração da amamentação do que determinantes sociodemográficos. Sendo assim, compreende-se que a amamentação e o desmame também abarcam questões para além da conscientização e informação, aspectos tão privilegiados pelos órgãos públicos, o que evidencia a insuficiência de se restringir a essas abordagens (Feliciano \& Souza, 2011). Deve-se também considerar a própria história constitutiva dos pais da criança, sobretudo, a materna, na medida em que conteúdos infantis são revividos e reatualizados nesse contexto, interferindo na dinâmica dos processos de amamentação e do desmame.

\section{Referências}

Brazelton, T.,\& Cramer, B. (1992). As primeiras relações. São Paulo: Martins Fontes.

Campagnolo, P. D. B., Louzada, M. L. D. C., Silveira, E. L., \& Vitolo, M. R. (2012). Práticas alimentares no primeiro ano de vida e fatores associados em amostra representativa da cidade de Porto Alegre, Rio Grande do Sul. Revista de Nutrição, 25(4), 431-439.

Carrascoza, K.C., Costa Junior, Á.L., \& Moraes, A. B.A. D. (2005). Fatores que influenciam o desmame precoce e a extensão do aleitamento materno. Estudos de Piscologia (Campinas), 22(4), 433-440.

Cotrim, L. C., Venancio, S. I., \& Escuder, M. M. L. (2002). Uso de chupeta e amamentação em crianças menores de quatro meses no estado de São Paulo. Revista Brasileira de Saúde Materno Infantil, 2(3) 245-252.

Dolto, F. (2004). A imagem inconsciente do corpo. São Paulo: Perspectiva.

Feliciano, D. S., \& Souza, A. S. L. (2011). Para além do seio: Uma proposta de intervenção psicanalítica pais-bebê a partir de dificuldades na amamentação. Jornal de Psicanálise, 44(81), 145-161.

Fleck, A.,\& Piccinini, C. A. (2013). O bebê imaginário e o bebê real no contexto da prematuridade: Do nascimento ao $3^{\circ}$ mês após a alta. Aletheia, 40, 14-30.

Freud, S. (2004). À guisa de introdução ao narcisismo. Em Escritos sobre a psicologia do inconsciente. (vol. 1, pp. 95-131). Rio de Janeiro: Imago. (Original publicado em 1914)

Grupo de Interação Social, Desenvolvimento e Psicopatologia - GIDEP. (1998a). Entrevista de dados demográficos do casal (Instrumento não publicado). Instituto de Psicologia, Universidade Federal do Rio Grande do Sul, Porto Alegre, Brasil.
Grupo de Interação Social, Desenvolvimento e Psicopatologia - GIDEP. (1998b). Entrevista sobre a Experiência da Maternidade - primeiro trimestre do bebê (Instrumento não publicado). Instituto de Psicologia, Universidade Federal do Rio Grande do Sul, Porto Alegre, Brasil.

Grupo de Interação Social, Desenvolvimento e Psicopatologia GIDEP. (1998c). Entrevista sobre o temperamento do bebê - primeiro trimestre do bebê (Instrumento não publicado). Instituto de Psicologia, Universidade Federal do Rio Grande do Sul, Porto Alegre, Brasil.

Grupo de Interação Social, Desenvolvimento e Psicopatologia - GIDEP. (1998d). Entrevista sobre a Experiência da Maternidade - oitavo mês do bebe (Instrumento não publicado). Instituto de Psicologia, Universidade Federal do Rio Grande do Sul, Porto Alegre, Brasil.

Grupo de Interação Social, Desenvolvimento e Psicopatologia GIDEP. (1998e). Entrevista sobre o temperamento do bebê - oitavo mês do bebê (Instrumento não publicado). Instituto de Psicologia, Universidade Federal do Rio Grande do Sul, Porto Alegre, Brasil.

Lacan, J. (1995). O seminário, livro 4: A relação de objeto. Rio de Janeiro: Zahar. (Original publicado em 1957)

Lacan, J. (1998). O estádio do espelho como formador da função do Eu. Em Escritos (pp. 96-103). Rio de Janeiro: Jorge Zahar. (Original publicado em 1949)

Lacan, J. (1999). Seminário Livro 5: As formações do inconsciente. Rio de Janeiro: Zahar. (Original publicado em 1958)

Lebovici, S. (1987). O bebê, a mãe e o psicanalista. Porto Alegre: Artes médicas.

Levin, E. (2005). Cenas e cenários no ato de amamentar. Em L. Sales (Org.), Pra que essa boca tão grande? Questões acerca da oralidade (pp. 87-114). Salvador: Ágalma.

Lighezzolo, J., Boubou, F., Souillot,C., \& Tychey, C. (2005). Allaitement prolongé et ratés du sevrage : Réflexions psychodynamiques. Cliniques Méditerranéennes, 72(2), 265-280.

Middlemore. M.P. (1974). Mãe e filho na amamentação: Uma analista observa a dupla amamentar. São Paulo: Inbrex.

Nakano, A.M.S., \& Mamede, M.V. (1999). A prática do aleitamento materno em um grupo de mulheres brasileiras: Movimento de acomodação e resistência. Revista Latino-Americana de Enfermagem, 7(3), 69-76.

O'brien, M., Buikstra, E., \& Hegney, D. (2008). The influence of psychological factors on breastfeeding duration. Journal of Advanced Nursing, 63, 397-408.

Organização Mundial da Saúde. (2001). Evidências científicas dos dez passos para o sucesso no aleitamento materno. Brasília: Organização Pan-Americana de Saúde.

Piccinini, C. A., Tudge, J., Lopes, R. S., \& Sperb, T. M. (1998-2012). Estudo longitudinal de Porto Alegre: Da gestação à escola (Projeto não publicado). Instituto de Psicologia, Universidade Federal do Rio Grande do Sul, Porto Alegre, Brasil.

Queiroz, T. C. N. (2005). Do desmame ao sujeito. São Paulo: Casa do Psicólogo.

Ramos, C.V., \& Almeida, J.A.G. (2003). Alegações maternas para o desmame: Estudo qualitativo. Jornal de Pediatria, 79(5), 385-390.

Rodulfo, R. (1990). O brincar e o significante: Um estudo psicanalítico sobre a constituição precoce. Porto Alegre: Artes Médicas. 
Sales, L. M. (2005). Preocupações acerca dos efeitos psíquicos do aleitamento materno exclusivo sobre a função materna e sobre o bebê. Em L. Sales (Org.), Pra que essa boca tão grande? Questões acerca da oralidade (pp. 115-132). Salvador: Ágalma.

Sampaio, M. A., Falbo, A.R., Camarotti, M.C., Vasconcelos, M.G.L., Echeverria, A., Lima, G., ... Prado, J.V.Z. (2010). Psicodinâmica interativa mãe-criança e desmame. Psicologia Teoria e Pesquisa, 26(4), 613-621.

Stake, R. E. (1994). Case Studies. Em N. Denzin \& Y. Lincoln (Eds.), Handbook of qualitative research (pp. 236-247). Londres: Sage.

Stern, D. (1997). A constelação da maternidade. Porto Alegre: Artes Médicas.
Winnicott, D. (1967). La familia y el desarrollo del individuo. Buenos Aires: Paidós.

Winnicott, D. W. (1977). Alimentação do Bebê. Em A criança e o seu mundo ( $4^{\mathrm{a}}$ ed., pp. 31-36). Rio de Janeiro: Zahar. (Originalmente publicado em 1945a)

Winnicott, D. W. (1977). O Desmame. EmA criança e o seu mundo (4 ${ }^{\text {a }}$ ed., pp. 89-94). Rio de Janeiro: Zahar. (Originalmente publicado em 1945b)

Winnicott., D.W. (2006). A amamentação como forma de comunicação (J. L. Camargo, Trad.) Em Os bebês e suas mães. (pp. 19-27) São Paulo: Martins Fontes. (Original publicado em 1968) 